DOI: https://doi.org/10.17308/kcmf.2019.21/2351

Поступила в редакцию 27.11.2019

Подписана в печать 15.12.2019

\title{
Оптические свойства активированных ионами меди и серебра пленок системы CdS-ZnS, осажденных при различных температурах
}

\author{
(ㄷ 2019 Т. В. Самофалова ${ }^{\otimes 1}$, В. Н. Семенов ${ }^{1}$, Е. Ю. Проскурина ${ }^{1}$, Л. В. Товарушкина ${ }^{1}$, \\ А. Н. Лукин ${ }^{1}$, Л. Н. Никитин ${ }^{2}$ \\ ${ }^{1}$ Воронежский государственный университет \\ Университетская пл. 1, 394018 Воронеж, Российская Федерация \\ ${ }^{2}$ Воронежский государственный технический университет \\ Московский проспект, 14, 394026 Воронеж, Российская Федерация
}

\begin{abstract}
Аннотация. Исследованы спектры поглощения и отражения активированных ионами меди и серебра пленок CdS-ZnS, полученных методом пиролиза аэрозоля из растворов тиомочевинных координационных соединений бромидов цинка и кадмия при разных температурах. Определены зависимости оптической ширины запрещенной зоны от состава пленок системы CdS-ZnS. Изучено влияние температуры осаждения и активирующей примеси на оптическую ширину запрещенной зоны синтезированных сульфидов.
\end{abstract}

Ключевые слова: сульфид кадмия, сульфид цинка, оптическая ширина запрещенной зоны, тиомочевинные координационные соединения, пиролиз аэрозоля.

\section{ВВЕДЕНИЕ}

Пленки твердых растворов на основе сульфидов кадмия и цинка являются одними из востребованных соединений для современной науки и микроэлектроники, так как находят широкое применение при изготовлении различных фотоэлектрических, оптоэлектронных, люминесцентных и других устройств [1-3]. Поэтому актуальным является получение пленок системы CdS-ZnS с управляемыми оптическими свойствами, что возможно осуществить путем варьирования условий осаждения, а также легирования активной примесью, например, ионами меди и серебра [4].

Ранее [5] были исследованы оптические и люминесцентные свойства легированных ионами меди пленок системы CdS-ZnS, осажденных из растворов тиомочевинных координационных соединений (TKC) $\left[\mathrm{M}\left(\mathrm{N}_{2} \mathrm{H}_{4} \mathrm{CS}\right)_{2} \mathrm{Br}_{2}\right](\mathrm{M}-\mathrm{Cd}, \mathrm{Zn})$ при температуре $400{ }^{\circ} \mathrm{C}$. В работе [6] установлено, что природа ТКС и температура синтеза оказывают влияние на оптическую ширину запрещенной зоны и фазовый состав полученных пиролитически пленок $\mathrm{CdS}-\mathrm{ZnS}$.

Целью данной работы являлось исследование влияния температуры осаждения, а также при-

\footnotetext{
Самофалова Татьяна Владимировна, e-mail: TSamofalova@bk.ru
}

месей ионов меди и серебра $\left(10^{-7}-10^{-3}\right.$ at. \%) на оптические свойства пленок системы CdS-ZnS, полученных из растворов координационных соединений $\left[\mathrm{M}\left(\mathrm{N}_{2} \mathrm{H}_{4} \mathrm{CS}\right)_{2} \mathrm{Br}_{2}\right](\mathrm{M}-\mathrm{Cd}, \mathrm{Zn})$.

\section{ЭКСПЕРИМЕНТАЛЬНАЯ ЧАСТЬ}

Осаждение пленок системы CdS-ZnS проводили методом пиролиза аэрозоля растворов тиомочевинных координационных соединений $\left[\mathrm{Cd}\left(\mathrm{N}_{2} \mathrm{H}_{4} \mathrm{CS}\right)_{2} \mathrm{Br}_{2}\right]$ и $\left[\mathrm{Zn}\left(\mathrm{N}_{2} \mathrm{H}_{4} \mathrm{CS}\right)_{2} \mathrm{Br}_{2}\right]$. Для получения комплексных соединений применяли тиомочевину марки «ос.ч.» а также соли $\mathrm{CdBr}_{2} \cdot 4 \mathrm{H}_{2} \mathrm{O}$ и $\mathrm{ZnBr}_{2}$ марки «ч.д.а.». ТКС синтезировали в водном растворе с концентрацией соответствующих солей металлов $0.05 \mathrm{~mol} / \mathrm{l}$ и тиомочевины $0.2 \mathrm{~mol} / \mathrm{l}$. Совместные растворы координационных соединений металлов в заданных молярных соотношениях $C_{\mathrm{Cd}^{2+}}: C_{\mathrm{zn}^{2+}}$ распыляли на нагретую подложку, на которой происходило формирование сульфида. Температура синтеза варьировалась от 350 до $500{ }^{\circ} \mathrm{C}$ с шагом $50{ }^{\circ} \mathrm{C}$. В качестве подложек применяли пластины кварца и ситалла.

При исследовании оптических свойств пленок системы CdS-ZnS были получены спектры поглощения и отражения в области края фундаментального поглощения. Спектры поглощения 
пленок, осажденных на кварце, регистрировали на спектрофотометре СФ-2000-02 в диапазоне 190-1100 nm относительно чистой подложки (стекло- $\mathrm{SiO}_{2}$ ). Оптические спектры абсолютного зеркального отражения образцов, полученных на ситалловых подложках, изучали с помощью спектрофотометра Lambda 650 с приставкой URA (Perkin Elmer) в диапазоне 190-900 nm длин волн.

Кристаллическую структуру и фазовый состав пленок изучали методом рентгенофазового анализа с помощью дифрактометра ARL XTRA Thermo Scientific (излучение $\mathrm{Cu} K_{\alpha 1}$ ). Межплоскостные расстояния $d$, полученные из дифрактограмм, сравнивали со справочными из базы данных [7].

Элементный состав образцов определяли методом локального рентгеноспектрального микроанализа (ЛРСМА) с помощью сканирующего электронного микроскопа JSM-6380 LV.

\section{РЕЗУЛЬТАТЫ И ИХ ОБСУЖДЕНИЕ}

В сульфидах цинка и кадмия оптическое поглощение обусловлено прямыми разрешенными переходами $[8,9]$. В этом случае край поглоще- ния описывается зависимостью:

$$
\alpha \cdot h v=\alpha_{0}\left(h v-E_{g}\right)^{1 / 2}
$$

где $\alpha$ - показатель поглощения; $\alpha_{0}-$ постоянная; $h v$ - энергия фотона; $E_{g}$ - оптическая ширина запрещенной зоны. Учитывая пропорциональность показателя поглощения и оптической плотности $D=\alpha d \lg e$ ( $d$ - толщина слоя), на зависимости величины $(h v D)^{2}$ от энергии фотона $h v$ в области края поглощения можно выделить линейный участок. Экстраполяцией этого линейного участка до оси абсцисс по точке пересечения определяется ширина запрещенной зоны.

Спектры поглощения всех синтезированных образцов имеют сходный вид. В качестве примера на рис. 1 представлены спектры поглощения пленок CdS-ZnS, легированных ионами серебра с концентрацией $10^{-6}$ at. \%.

Для образцов, осажденных при разных температурах, при увеличении содержания сульфида цинка наблюдается смещение края поглощения в более коротковолновую область. При этом происходит постепенное увеличение оптической ширины запрещенной зоны $E_{\mathrm{g}}$ (рис. 2). Такие

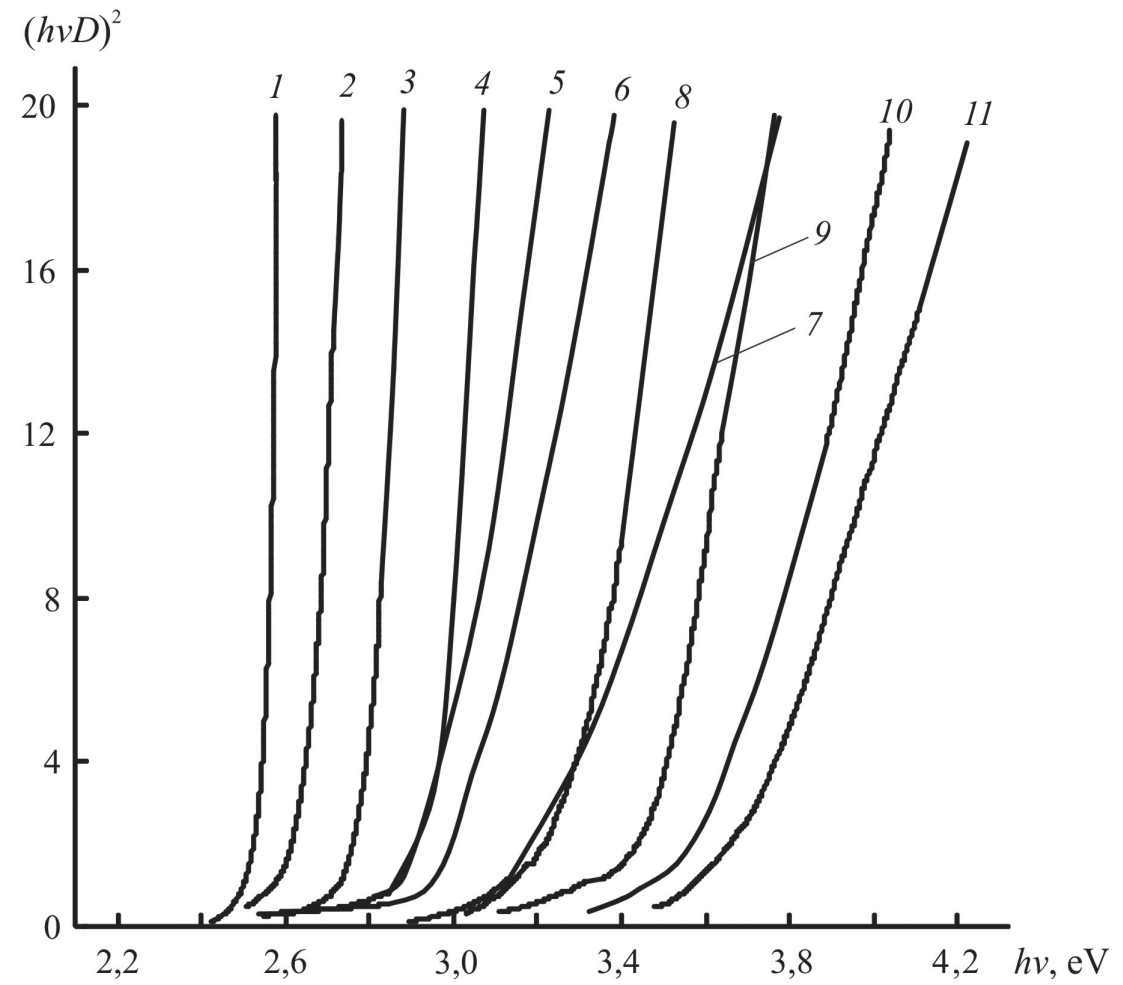

Рис. 1. Спектры поглощения пленок системы CdS-ZnS, легированных ионами серебра с концентрацией $10^{-6}$ at. \%: 1 - 0; 2 - 10; 3 - 20; 4 - 30; 5 - 40; 6- 50; 7 - 60; 8 - 70; 9 - 80; 10 - 90; 11 - 100 мол. \% ZnS. Температура осаждения $450{ }^{\circ} \mathrm{C}$

[Fig. 1. Absorption spectra of CdS-ZnS films doped with silver ions at a concentration of $10^{-6}$ at. \%: $1-0$; $2-10 ; 3-20 ; 4-30 ; 5-40 ; 6-50 ; 7-60 ; 8-70 ; 9-80 ; 10-90 ; 11-100 \mathrm{~mol} \%$ ZnS. The temperature of deposition $\left.450^{\circ} \mathrm{C}\right]$ 
особенности изменения $E_{\mathrm{g}}(x)$ наблюдаются для всех исследуемых пленок независимо от вида и концентрации легирующей примеси и косвенно указывают на неограниченную растворимость компонентов в рассматриваемой системе.

Следует отметить, что значения оптической ширины запрещенной зоны для легированных пленок одного и того же состава изменяются в пределах 0.01-0.07 eV по сравнению с нелегированными пленками, что может быть связано с изменениями в зонной структуре сульфидов $\mathrm{Cd}_{x} \mathrm{Zn}_{1-\mathrm{x}} \mathrm{S}$ в результате введения активатора. Наименьшими значениями $E_{\mathrm{g}}$ характеризуются пленки с концентрацией примеси $10^{-3}$ at. \% и более. Поскольку при больших концентрациях активатора примесные дефекты расположены ближе друг к другу, в результате их взаимодействия происходит расширение примесных энергетических уровней в подзону, что в свою очередь приводит к уменьшению ширины запрещенной зоны образцов.

Кроме того, снижение $E_{g}$ «сильнолегированных» пленок может быть связано с присутствием в них примесных фаз сульфидов меди (серебра), которые характеризуются меньшими значениями оптической ширины запрещенной зоны (1.7-2.0 еV для $\mathrm{Cu}_{2} \mathrm{~S}$ и $0.9-1.1 \mathrm{eV}$ для $\left.\mathrm{Ag}_{2} \mathrm{~S}[10,11]\right)$. При малой концентрации активатора самостоятельная примесная фаза в образцах не обнаружена (табл. 1). Все синтезированные пленки системы CdS-ZnS являются поликристаллическими и кристаллизуются в структуре вюртцита.

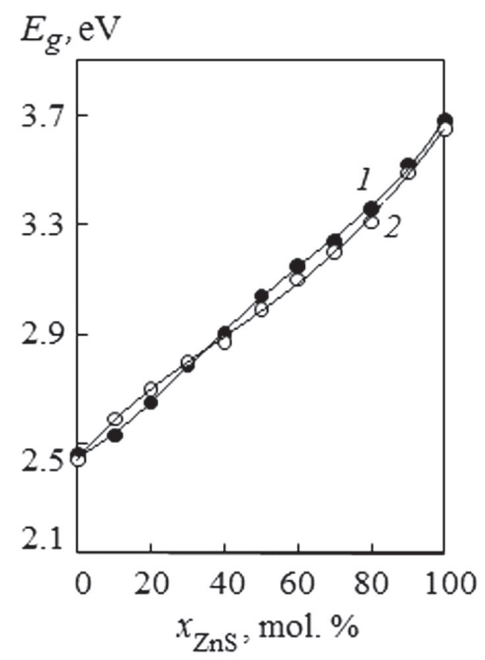

$a$
На рис. 3 представлены спектры отражения осажденных при $450{ }^{\circ} \mathrm{C}$ пленок CdS-ZnS, легированных ионами меди с концентрацией $10^{-6}$ at. \%. Спектры отражения исследуемых слоев, полученных при разных температурах и концентрациях примесей, имеют сходный вид. Диапазон длин волн, соответствующий положению края поглощения синтезированных образцов, составляет от 290 до $500 \mathrm{~nm}$. Граница, связанная с поглощением излучения сульфидной пленкой, смещается в более коротковолновую область при увеличении содержания сульфида цинка в образцах.

Полученные спектры, представляющие собой типичные спектры отражения-поглощения (RAS) с двойным прохождением света через слой исследуемого вещества и отражения от ситалловой подложки, обрабатывали по методике, описанной в $[12,13]$. Учитывая степенной закон (1) для собственного поглощения, можно записать:

$$
Y(h v) \equiv \ln \frac{R_{\max }-R_{\min }}{R(h v)-R_{\min }}=2 \alpha_{0} d \frac{\left(h v-E_{g}\right)^{1 / 2}}{h v},
$$

где $R$ - коэффициент отражения; $R_{\max }$ - максимальный коэффициент отражения; $R_{\min }-$ минимальный коэффициент отражения. Наличие линейного участка на зависимости $[h v Y(h v)]^{2}$ в области края поглощения позволяет определить оптическую ширину запрещенной зоны сульфида (рис. 4).

Значения оптической ширины запрещенной зоны, определенные из спектров отражения и

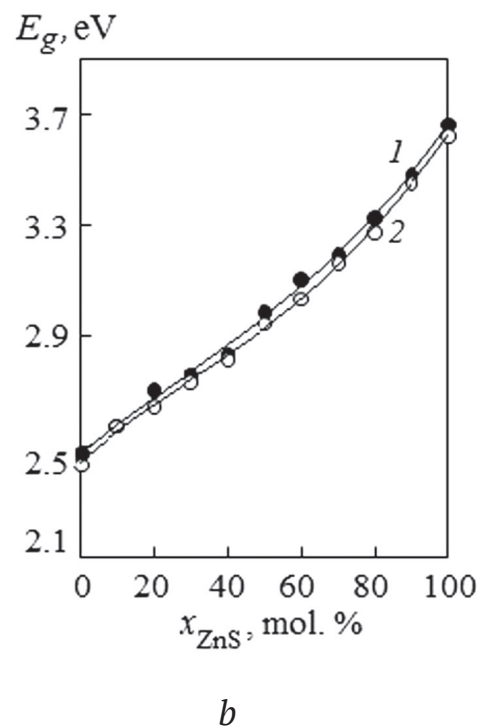

Рис. 2. Зависимости оптической ширины запрещенной зоны пленок системы CdS-ZnS, легированных ионами меди (1) и серебра (2) с концентрацией $10^{-7}$ at. \% (a) и $10^{-4}$ at. \% (б). Температура осаждения $450{ }^{\circ} \mathrm{C}$

[Fig. 2. Dependencies of the optical band gap of CdS-ZnS films doped with copper (1) and silver (2) ions with a concentration of $10^{-7}$ at. \% (a) and $10^{-4}$ at. \% (b). The temperature of deposition $\left.450^{\circ} \mathrm{C}\right]$ 
Таблица 1. Межплоскостные расстояния в пленках $\mathrm{Cd}_{0.5} \mathrm{Zn}_{0.5} \mathrm{~S}$, полученных при температурах 400 и $500{ }^{\circ} \mathrm{C}$. Обозначения: $d$ - межплоскостное расстояние в пленках, $\mathrm{nm} ; \mathrm{I}$ - интенсивность дифракционного максимума, \%

[Table 1. Interplanar distances in the $\mathrm{Cd}_{0.5} \mathrm{Zn}_{0.5} \mathrm{~S}$ films deposited at temperatures of 400 and $500{ }^{\circ} \mathrm{C}$. Designation: $d$ - interplanar distance; $I$ - diffraction peak intensity]

\begin{tabular}{|c|c|c|c|c|c|c|c|c|c|c|c|c|c|}
\hline \multicolumn{14}{|c|}{$\begin{array}{l}\text { Температура осаждения / Концентрация ионов примеси, at. \% } \\
\text { [Deposition temperature / Concentration of impurity ions, at. \%] }\end{array}$} \\
\hline Примесь & \multicolumn{6}{|c|}{$400{ }^{\circ} \mathrm{C}$} & \multicolumn{6}{|c|}{$500^{\circ} \mathrm{C}$} & \multirow{3}{*}{$\begin{array}{l}\text { Отнесение } \\
\text { [Assignment] }\end{array}$} \\
\hline \multirow{8}{*}{$\mathrm{Cu}^{+}$} & \multicolumn{2}{|c|}{$1 \cdot 10^{-7}$} & \multicolumn{2}{|c|}{$1 \cdot 10^{-4}$} & \multicolumn{2}{|c|}{$1 \cdot 10^{-3}$} & \multicolumn{2}{|c|}{$1 \cdot 10^{-7}$} & \multicolumn{2}{|c|}{$1 \cdot 10^{-4}$} & \multicolumn{2}{|c|}{$1 \cdot 10^{-3}$} & \\
\hline & $d, \mathrm{~nm}$ & $I, \%$ & $d, \mathrm{~nm}$ & $I, \%$ & $d, \mathrm{~nm}$ & $I, \%$ & $d, \mathrm{~nm}$ & $I, \%$ & $d, \mathrm{~nm}$ & $I, \%$ & $d, \mathrm{~nm}$ & $I, \%$ & \\
\hline & 0.3444 & 20 & 0.3389 & 14 & 0.3504 & 43 & 0.3482 & 29 & 0.3455 & 16 & 0.3453 & 18 & $w(100)$ \\
\hline & 0.3236 & 100 & 0.3218 & 59 & 0.3236 & 62 & 0.3247 & 58 & 0.3243 & 51 & 0.3233 & 33 & $w(002)$ \\
\hline & 0.3056 & 18 & 0.3034 & 13 & 0.3053 & 64 & 0.3052 & 93 & 0.3054 & 21 & 0.3065 & 13 & $w(101)$ \\
\hline & 0.1997 & 14 & 0.1985 & 14 & 0.1993 & 15 & 0.1986 & 23 & & & 0,1994 & 10 & $w(110)$ \\
\hline & - & - & 0.1568 & 100 & - & - & 0.1536 & 11 & 0.1558 & 85 & 0,1575 & 90 & (202) \\
\hline & - & - & 0.2090 & 50 & $\begin{array}{l}0.2825 \\
0.2483 \\
0.2030 \\
0.1853\end{array}$ & $\begin{array}{l}22 \\
30 \\
22 \\
20\end{array}$ & - & - & $\begin{array}{l}0.2958 \\
0.2099\end{array}$ & $\begin{array}{l}23 \\
31\end{array}$ & $\begin{array}{l}0.3155 \\
0,2100 \\
0.1834\end{array}$ & $\begin{array}{l}36 \\
24 \\
15\end{array}$ & $\mathrm{CuS}, \mathrm{Cu}_{2} \mathrm{~S}$ \\
\hline \multirow{6}{*}{$\mathrm{Ag}^{+}$} & 0.3447 & 68 & 0.3433 & 10 & 0.3453 & 19 & 0.3477 & 38 & 0.3504 & 63 & 0.3459 & 71 & $w(100)$ \\
\hline & 0.3241 & 38 & 0.3222 & 100 & 0.3246 & 68 & 0.3258 & 67 & 0.3237 & 62 & 0.3243 & 83 & $w(002)$ \\
\hline & 0.3045 & 100 & 0.3037 & 13 & 0.3068 & 41 & 0.3065 & 100 & 0.3054 & 59 & 0.3055 & 44 & $w(101)$ \\
\hline & 0.1992 & 31 & 0.1981 & 5 & - & - & 0.2005 & 27 & 0.1993 & 16 & 0.1997 & 32 & $w(110)$ \\
\hline & 0.1562 & 86 & 0.1568 & 7 & 0.1575 & 35 & 0.1528 & 8 & - & - & - & - & $w(202)$ \\
\hline & - & - & 0.1693 & 25 & $\begin{array}{l}0.2381 \\
0.1965\end{array}$ & $\begin{array}{l}22 \\
12\end{array}$ & - & - & 0.2384 & 17 & $\begin{array}{l}0.3022 \\
0.1702\end{array}$ & $\begin{array}{l}12 \\
17\end{array}$ & $\mathrm{Ag}_{2} \mathrm{~S}$ \\
\hline
\end{tabular}

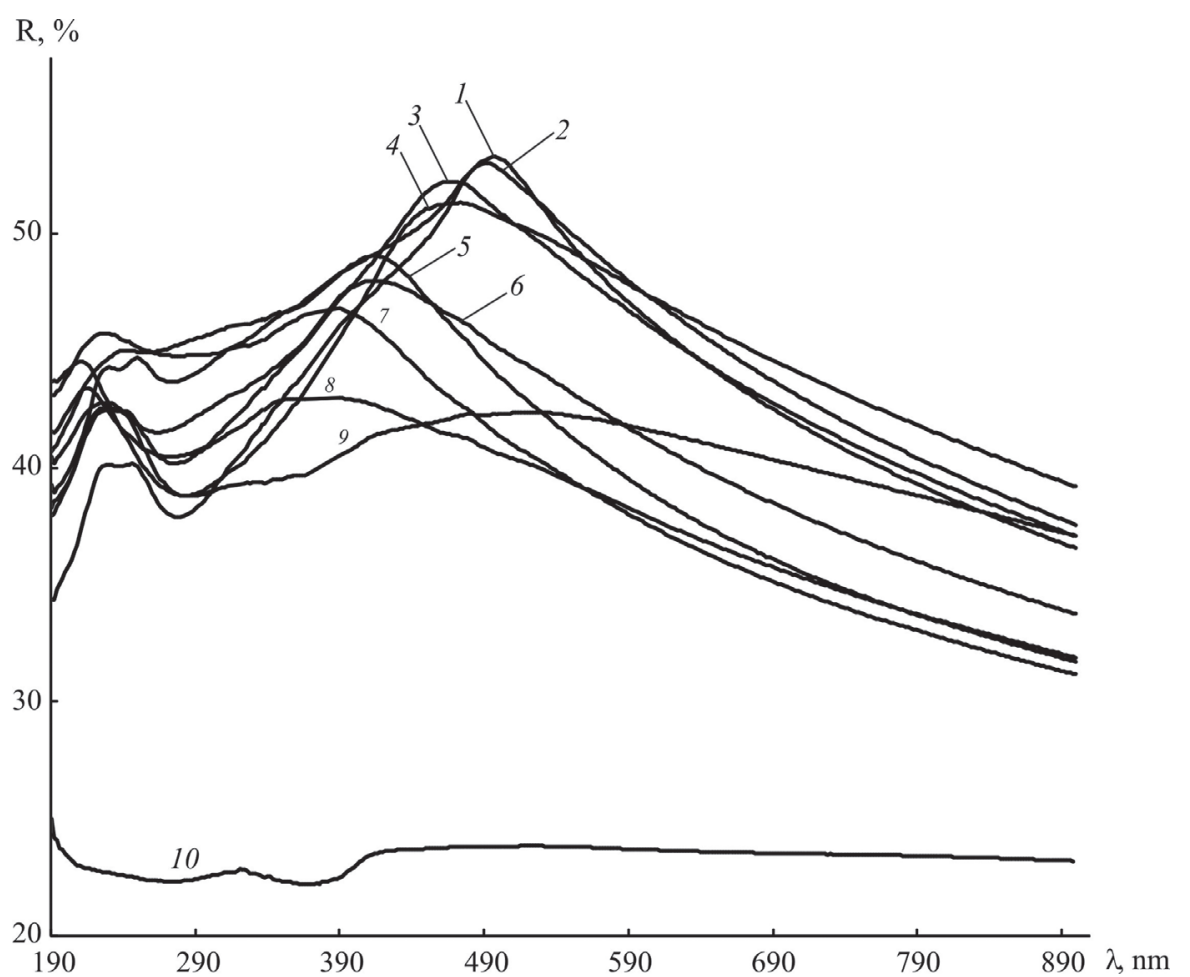

Рис. 3. Спектры отражения пленок системы CdS-ZnS, легированных ионами меди с концентрацией $10^{-6}$ at. \%: 1 - 0; 2 - 10; 3 - 30; 4 - 40; 5 - 50; 6 - 60; 7 - 70; 8 - 90; 9 - 100 mol \% ZnS; 10 - ситалл. Температура осаждения $450^{\circ} \mathrm{C}$

[Fig. 3. Reflection spectra of CdS-ZnS films doped with copper ions with a concentration of $10^{-6}$ at. \%: $1-0$; $2-10 ; 3-30 ; 4-40 ; 5-50 ; 6-60 ; 7-70 ; 8-90 ; 9-100 \mathrm{~mol} \% \mathrm{ZnS} ; 10$ - sital. The temperature of deposition $\left.450^{\circ} \mathrm{C}\right]$ 


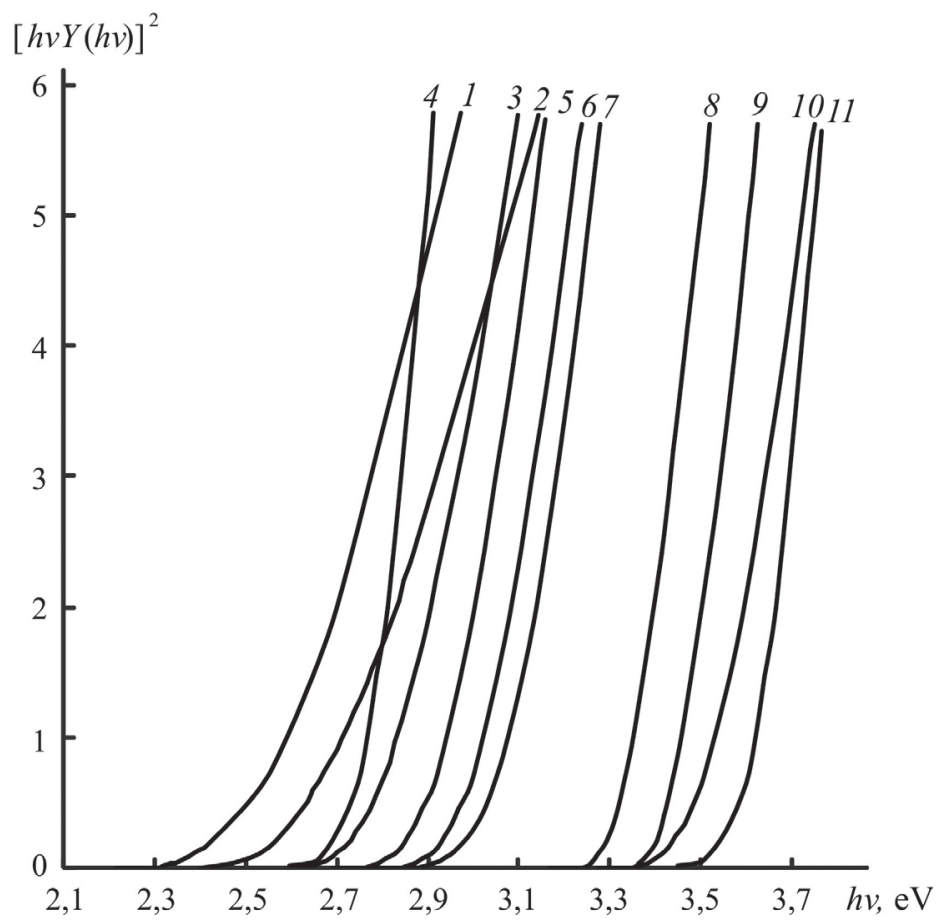

Рис. 4. Зависимости $[h v Y(h v)]^{2}=f(h v)$ для пленок системы CdS-ZnS, легированных ионами меди с концентрацией $10^{-6}$ at. \%: 1 - 0; 2 - 10; 3 - 30; 4-40; 5- 50; 6- 60; 7 - 70; 8 - 90; 9 - $100 \mathrm{~mol} \% \mathrm{ZnS}$ [Fig. 4. Dependencies $[h v Y(h v)]^{2}=f(h v)$ for CdS-ZnS films doped with copper ions at a concentration of $10^{-6}$ at. \%: 1 - 0; $2-10 ; 3-30 ; 4-40 ; 5-50 ; 6-60 ; 7-70 ; 8-90 ; 9-100 \mathrm{~mol} \% \mathrm{ZnS}]$

спектров поглощения, для большинства пленок системы CdS-ZnS оказались близкими (табл. 2). Так, для пленок $\mathrm{Cd}_{0.5} \mathrm{Zn}_{0.5} \mathrm{~S}$, легированных ионами меди с концентрацией $10^{-6}$ at. \%, ширина запрещенной зоны имеет значения 3.03 и $3.02 \mathrm{eV}$ соответственно.

В ультрафиолетовой области от 190 до 300 $\mathrm{nm}$ на спектрах отражения наблюдаются пики, соответствующие высокоэнергетическим переходам в других симметричных точках зоны Бриллюэна (рис. 3). Так, для пленок сульфида кадмия такие пики зарегистрированы при 234 $\mathrm{nm}(4.92 \mathrm{eV})$ и $252 \mathrm{~nm}(5.30 \mathrm{eV})$, что согласуется с литературными данными [8]. Обычно такие максимумы наблюдаются на спектрах отражения монокристаллов, поэтому можно по оптическим данным судить о высокой степени кристалличности пленок, полученных в данной работе.

Анализируя результаты оптических исследований, следует отметить, что в целом для образцов системы CdS-ZnS, полученных при температуре $500^{\circ} \mathrm{C}$ (рис. 5), характерны меньшие значения оптической ширины запрещенной зоны по сравнению с пленками, осажденными при других температурах. Такие особенности изменения $E_{\mathrm{g}}$ сульфидных пленок с увеличением температуры связаны с влиянием химической природы
Таблица 2. Оптическая ширина запрещенной зоны пленок системы CdS-ZnS, легированных ионами меди с концентрацией $10^{-6}$ at. \%. Температура осаждения $450{ }^{\circ} \mathrm{C}$

[Table 2. Optical band gap of CdS-ZnS films doped with copper ions with a concentration of $10^{-6}$ at. \%. The temperature of deposition $450{ }^{\circ} \mathrm{C}$ ]

\begin{tabular}{|c|c|c|}
\hline \multirow[b]{2}{*}{$\begin{array}{c}x_{\text {Zns' }}, \\
\text { мол. \% } \\
{\left[x_{\text {ZnS }}\right.} \\
\text { mol. \%] }\end{array}$} & \multicolumn{2}{|c|}{$\begin{array}{c}\text { Оптическая ширина запрещенной } \\
\text { зоны, eV } \\
\text { [Optical band gap, eV] }\end{array}$} \\
\hline & $\begin{array}{c}\text { По спектрам } \\
\text { поглощения } \\
\text { [From absorption } \\
\text { spectra] }\end{array}$ & $\begin{array}{c}\text { По спектрам } \\
\text { отражения- } \\
\text { поглощения } \\
\text { [From reflection - } \\
\text { absorption spectra] }\end{array}$ \\
\hline 0 & 2.49 & 2.51 \\
\hline 10 & 2.63 & 2.67 \\
\hline 20 & 2.78 & 2.75 \\
\hline 30 & 2.89 & 2.82 \\
\hline 40 & 2.96 & 2.91 \\
\hline 50 & 3.03 & 3.02 \\
\hline 60 & 3.17 & 3.09 \\
\hline 70 & 3.27 & 3.32 \\
\hline 80 & 3.45 & 3.43 \\
\hline 90 & 3.58 & 3.56 \\
\hline 100 & 3.68 & 3.62 \\
\hline
\end{tabular}



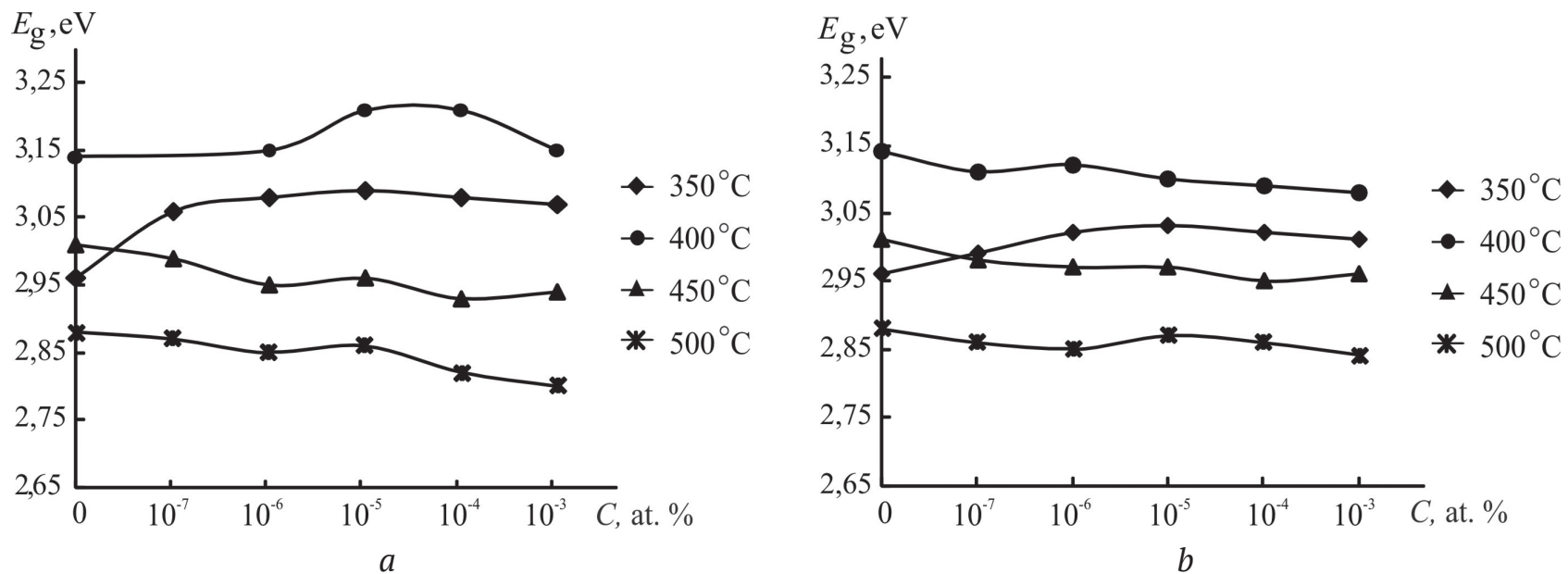

Рис. 5. Зависимости оптической ширины запрещенной зоны пленок $\mathrm{Cd}_{0.5} \mathrm{Zn}_{0.5} \mathrm{~S}$ от концентрации примеси ионов меди (a) и серебра (б). Температура осаждения: $1-350{ }^{\circ} \mathrm{C} ; 2-400{ }^{\circ} \mathrm{C} ; 3-450{ }^{\circ} \mathrm{C} ; 4-500{ }^{\circ} \mathrm{C}$ [Fig. 5. Dependencies of the optical bandgap of $\mathrm{Cd}_{0.5} \mathrm{Zn}_{0.5} \mathrm{~S}$ films of the doping concentration of copper $(a)$ and silver $(b)$ ions. The temperature of the deposition: $\left.1-350{ }^{\circ} \mathrm{C} ; 2-400{ }^{\circ} \mathrm{C} ; 3-450{ }^{\circ} \mathrm{C} ; 4-500{ }^{\circ} \mathrm{C}\right]$

координационного прекурсора на их состав и микроструктуру.

При осаждении пленок из растворов комплексов $\left[\mathrm{M}\left(\mathrm{N}_{2} \mathrm{H}_{4} \mathrm{CS}\right)_{2} \mathrm{Br}_{2}\right]$ основным видом дефектов является бром, замещающий анионные узлы $\left(\mathrm{Br}_{\mathrm{s}}^{*}\right)$. Ввиду того, что синтез проводится на воздухе, в состав образующихся сульфидов может входить кислород. Согласно данным ЛРСМА (табл. 3) с увеличением температуры синтеза содержание брома в осаждаемых пленках уменьшается, что связано с более полной термической деструкцией ТКС. Это приводит к уменьшению содержания дефектов $\mathrm{Br}_{\mathrm{S}}^{\bullet}$ и образованию бо́льшего количества дефектов $\mathrm{O}_{\mathrm{s}}^{\times}$, что в целом способствует снижению оптической ширины запрещенной зоны синтезированных сульфидов.

\section{ЗАКЛЮЧЕНИЕ}

Методом пиролиза аэрозоля растворов тиомочевинных координационных соединений $\left[\mathrm{M}\left(\mathrm{N}_{2} \mathrm{H}_{4} \mathrm{CS}\right)_{2} \mathrm{Br}_{2}\right](\mathrm{M}=\mathrm{Cd}, \mathrm{Zn})$ в диапазоне температур 350-500 ${ }^{\circ} \mathrm{C}$ синтезированы пленки системы CdS-ZnS, легированные ионами меди и серебра с концентрацией $10^{-7}-10^{-3}$ at. \%. Выявлено, что край поглощения всех исследуемых пленок системы CdS-ZnS смещается в коротковолновую область при увеличении в них доли цинка (по катиону), а оптическая ширина запрещенной зоны, соответственно, увеличивается. Повышение концентрации примеси до $10^{-3}$ at. \% приводит к уменьшению ширины запрещенной зоны синтезированных образцов в связи с изменениями в их зонной структуре. При увеличении
Таблица 3. Элементный состав пленок сульфида кадмия, осажденных при разных температурах

[Table 3. Elemental composition of cadmium sulfide films deposited at different temperatures]

\begin{tabular}{|c|c|c|c|}
\hline \multirow{2}{*}{$\begin{array}{c}\text { Элемент } \\
\text { [Element] }\end{array}$} & \multicolumn{3}{|c|}{$\begin{array}{c}\text { Содержание элемента, at. \% } \\
\text { [The content of the element, at. \%] }\end{array}$} \\
\cline { 2 - 4 } & $350{ }^{\circ} \mathrm{C}$ & $450{ }^{\circ} \mathrm{C}$ & $500{ }^{\circ} \mathrm{C}$ \\
\hline $\mathrm{Cd}$ & 33.8 & 32.6 & 24.2 \\
\hline $\mathrm{S}$ & 27.2 & 29.7 & 22.0 \\
\hline $\mathrm{O}$ & 15.0 & 18.7 & 40.1 \\
\hline $\mathrm{Br}$ & 24.0 & 19.0 & 13.7 \\
\hline
\end{tabular}

температуры до $500{ }^{\circ} \mathrm{C}$ оптическая ширина запрещенной зоны сульфидных пленок в целом снижается, что обусловлено изменением их дефектной структуры.

\section{ИСТОЧНИК ФИНАНСИРОВАНИЯ}

Работа выполнена при финансовой поддержке РФФИ в рамках научного проекта № 1833-01215 мол_а.

\section{БЛАГОДАРНОСТИ}

Исследования проведены с использованием оборудования Центра коллективного пользования Воронежского государственного университета. URL: http://ckp.vsu.ru.

\section{КОНФЛИКТ ИНТЕРЕСОВ}

Авторы декларируют отсутствие явных и потенциальных конфликтов интересов, связанных с публикацией настоящей статьи. 


\section{СПИСОК ЛИТЕРАТУРЫ}

1. Гаврилов С. А., Шерченков А. А., Апальков А. Б., Кравченко Д. А. Оптоэлектронные свойства пленок CdS для солнечных элементов с тонким абсорбирующим слоем // Российские нанотехнологии, 2006, т. 1(1-2), с. 228-232. Режим доступа: https://elibrary.ru/item.asp?id=9232621 (дата обращения: 26.11.19)

2. Kudiy D. A., Klochko N. P., Khripunov G. S., Kovtun N. A., Krikun K. Y., Belonogov Y. K. Elaboration of cadmium sulphide film layers for economical solar cells // Photoelectronics, 2009, v. 18, pp. 39-42. DOI: https://doi.org/10.18524/1815-7459.2009.2.115679

3. Бачериков Ю. Ю., Кицюк Н. В. Люминофоры на основе легированного сульфида цинка с одинаковой спектральной плотностью излучения в диапазоне от 500 до $750 \mathrm{~nm} / /$ Журнал технической физики, 2005, т. 75(5), с. 129-130. Режим доступа: https://journals.ioffe.ru/articles/8562 (дата обращения: 26.11.19)

4. Сычев М. М., Огурцов К. А., Лебедев В. Т., Кульвелис Ю. В., Torok G., Соколов А. Е., Трунов В. А., Бахметьев В. В., Котомин А. А., Душенок С. А., Козлов А. С. Влияние концентрации меди и обработки $\mathrm{ZnS}$ на характеристики синтезированных электролюминофоров $\mathrm{ZnS}: \mathrm{Cu}, \mathrm{Cl} / /$ ФТП, 2012, т. 46(5), с. 714-718. Режим доступа: https://journals.ioffe.ru/ articles/7713 (дата обращения: 26.11.19)

5. Самофалова Т.В., Семенов В.Н., Нитута А.Н., Звягина О. В., Проскурина Е. Ю. Синтез и свойства пленок системы CdS-ZnS, легированных ионами меди // Конденсированные среды и межфазные границы, 2018, т. 20(3), с. 440-447. DOI: https://doi. org $/ 10.17308 / \mathrm{kcmf} .2018 .20 / 582$

6. Самофалова Т. В., Наумов А. В., Семенов В. Н., Салтыков С. Н. Влияние температуры осаждения на оптические свойства и фазовый состав пленок $\mathrm{Cd}_{1-\mathrm{x}} \mathrm{Zn}_{x} \mathrm{~S} / /$ Конденсированные среды и межфазные границы, 2010, т. 12(3), с. 247-257. Режим доступа: https://elibrary.ru/item.asp?id=15574169 (дата обращения: 26.11.19)

7. Powder Diffraction File. Swarthmore: Joint Committee on Powder Diffraction Standards, 1996.

8. Физика и химия соединений $A^{I I} B^{V I} /$ Пер. с англ. под ред. С. А. Медведева. М.: Мир, 1970, 624 с.

9. Кирьяшкина 3. И., Роках А. Г., Кац Н. Б. Фотопроводящие пленки (типа CdS). Саратов, Изд-во Сарат. ун-та, 1979, 192 с.

10. Угай Я.А. Введение в химию полупроводников. М.: Высшая школа, 1975, 302 с.

11. Абрикосов Н. Х., Банкина В. Ф., Порецкая Л. В., Скуднова Е. В., Чижевская С. Н. Полупроводниковые халькогениды и сплавы на их основе. М.: Наука, 1975, 218 с.

12. Kumar V., Sharma T. P. Structural and optical properties of sintered $\mathrm{CdS}_{x} \mathrm{Se}_{1-x} \mathrm{~S}$ films // J. Phys. Chem. Sol., 1998,v.59(8),p.1321.DOI:https://doi.org/10.1016/ S0022-3697(98)00035-3

13. Метелева Ю. В., Новиков Г. Ф. Получение и СВЧ фотопроводимость полупроводниковых пленок CdSe // ФТП, 2006, т. 40 (10), с. 1167-1174. Режим доступа: https://journals.ioffe.ru/articles/ viewPDF/6162 (дата обращения: 26.11.19)

\title{
Optical Properties of Copper and Silver Ion-Activated Films of a CdS-ZnS System, Deposited at Different Temperatures
}

\author{
(c) 2019 T. V. Samofalova ${ }^{\bowtie 1}$, V. N. Semenov ${ }^{1}$, E. Yu. Proskurina ${ }^{1}$, L. V. Tovarushkina ${ }^{1}$, \\ A. N. Lukin ${ }^{1}$ L. N. Nikitin ${ }^{2}$ \\ ${ }^{1}$ Voronezh State University \\ 1, Universitetskaya pl., 394018 Voronezh, Russian Federation \\ ${ }^{2}$ Voronezh State Technical University \\ 14, Moskovsky pr., 394026 Voronezh, Russian Federation
}

\begin{abstract}
Purpose. In this study, the influence of the deposition temperature and of the impurities of copper and silver ions $\left(10^{-7}-10^{-3}\right.$ at. \%) on the optical properties of films of a CdS-ZnS system was investigated.

Methods. The films of a CdS-ZnS system were synthesized using the method of pyrolysis of the aerosols of thiourea solutions of $\left[\mathrm{M}\left(\mathrm{N}_{2} \mathrm{H}_{4} \mathrm{CS}\right)_{2} \mathrm{Br}_{2}\right](\mathrm{M}=\mathrm{Cd}$, $\mathrm{Zn})$ coordination compounds within
\end{abstract}

Tatyana V. Samofalova, e-mail: TSamofalova@bk.ru 
the temperature range of $350-500{ }^{\circ} \mathrm{C}$. The absorption and reflection spectra were obtained in the area of the fundamental absorption edge as the result of the study of films of CdS-ZnS system the optical properties. The phase composition and crystal structure of the films were examined using X-ray diffraction analysis. The elemental composition of the samples was defined by the method of local X-ray spectral microanalysis using a scanning electron microscope.

Results. The absorption and reflection spectra of the CdS-ZnS films doped with copper and silver ions were studied and their optical band gap $\mathrm{E}_{\mathrm{g}}$ was measured. It was found that an increase in the amount of zinc sulphide in the samples results in progressive increase in the value of the optical band gap, regardless of the type and concentration of the doping impurity. Also, the influence of the deposition temperature and the activating impurity on the optical band gap of synthesized sulphides has been studied. It was established that the films of the CdS-ZnS system are polycrystalline and they crystallize in the wurtzite structure.

Conclusion. It was found that the absorption edge of all the studied CdS-ZnS films shifted to the short-wave area with an increase of zinc sulphide content in them and the optical band gap expands, respectively. Increase in the impurity concentration up to $10^{-3}$ at. \% and temperature increase up to $500{ }^{\circ} \mathrm{C}$ led to the reduction of the optical band gap of the synthesized samples due to the changes in their defect and band structure.

Keywords: cadmium sulfide, zinc sulfide, optical band gap, thiourea coordination compounds, aerosol pyrolysis.

\section{SOURCE OF FINANCING}

The study was supported by the Russian Foundation for Basic Research (project no. 18-3301215 mol_a).

\section{ACKNOWLEDGEMENT}

The results of the research were obtained using the equipment of the Centre for Collective Use of Scientific Equipment of Voronezh State University. URL: http://ckp.vsu.ru.

\section{CONFLICT OF INTEREST}

The authors declare the absence of obvious and potential conflicts of interest related to the publication of this article.

\section{REFERENCES}

1. Gavrilov S. A., Sherchenkov A. A., Apal'kov A. B., Kravchenko D. A. Optojelektronnye svojstva plenok CdS dlja solnechnyh jelementov s tonkim absorbirujushhim sloem. Rossijskie nanotehnologii, 2006, v. 1(1-2), pp. 228-232. Available at: https://elibrary. $\mathrm{ru} / \mathrm{item} . \mathrm{asp}$ ?id=9232621 (accessed 26.11.2019) (in Russ.)

2. Kudiy D. A., Klochko N. P., Khripunov G. S., Kovtun N. A., Krikun K. Y., Belonogov Y. K. Elaboration of cadmium sulphide film layers for economical solar cells. Photoelectronics, 2009, v. 18, pp. 39-42. DOI: https://doi.org/10.18524/1815-7459.2009.2.115679

3. Bacherikov Ju. Ju., Kicjuk N. V. Ljuminofory na osnove legirovannogo sul'fida cinka s odinakovoj spektral'noj plotnost'ju izluchenija v diapazone ot 500 do $750 \mathrm{~nm}$. Zhurnal tehnicheskoj fiziki, 2005, v. 75(5), pp. 129-130. Available at: https://journals.ioffe.ru/articles/8562 (accessed 26.11.2019) (in Russ.)
4. Sychov M. M., Ogurtsov K. A., Bakhmetyev V. V., Kotomin A. A., Dushenok S. A., Kozlov A. S., Lebe$\operatorname{dev}$ V. T., Kulvelis Y. V., Sokolov A. E., Trunov V. A., Türük G. Effect of the Cu content and $\mathrm{ZnS}$ treatment on the characteristics of synthesized $\mathrm{ZnS}:(\mathrm{Cu}, \mathrm{Cl})$ electroluminescent phosphors. Semiconductors, 2012, v. 46(5), pp. 696-700. Available at: https://journals. ioffe.ru/articles/7713 (accessed 26.11.2019) (in Russ., abstract in Eng.)

5. Samofalova T. V., Semenov V. N., Nituta A. N., Zvjagina O.V., Proskurina E. Ju. Sintez i svojstva plenok sistemy CdS-ZnS, legirovannyh ionami medi. Kondensirovannye sredy i mezhfaznye granitsy [Condensed Matter and Interphases], 2018, v. 20(3), pp. 440-447. DOI: https://doi.org/10.17308/kcmf.2018.20/582 (in Russ., abstract in Eng.)

6. Samofalova T. V., Naumov A. V., Semenov V. N., Saltykov S. N. Vlijanie temperatury osazhdenija na opticheskie svojstva i fazovyj sostav plenok $\mathrm{Cd}_{1-\mathrm{x}} \mathrm{Zn}_{x} \mathrm{~S}$. Kondensirovannye sredy $i$ mezhfaznye granitsy [Condensed Matter and Interphases], 2010, v. 12(3), pp. 247-257. Available at: https://elibrary.ru/item. asp?id=15574169 (accessed 26.11.2019) (in Russ., abstract in Eng.).

7. Powder Diffraction File. Swarthmore: Joint Committee on Powder Diffraction Standards, 1996.

8. Fizika i himija soedinenij $A^{I I} B^{V I}[$ Physics and chemistry of compounds $\left.\mathrm{A}^{\mathrm{II}} \mathrm{B}^{\mathrm{VI}}\right]$ / Ed. by S. A. Medvedeva. Moscow, Mir Publ., 1970, 624 p. (in Russ.)

9. Kir'jashkina Z. I., Rokah A. G., Kac N. B. Fotoprovodjashhie plenki (tipa CdS) [Photoconductive films (type CdS)]. Saratov University Publ., 1979, 192 p. (in Russ.)

10. Ugai Ya. A. Vvedenie v himiju poluprovodnikov [Introduction to Semiconductor Chemistry]. Moscow, Vysshaja Shkola Publ., 1975, 302 p. (in Russ.) 
11. Abrikosov N. H., Bankina V. F., Poreckaja L. V., Skudnova E. V., Chizhevskaja S. N. Poluprovodnikovye hal'kogenidy i splavy na ih osnove [Semiconductor chalcogenides and alloys based on them]. Moscow, Nauka Publ., 1975, 218 p. (in Russ.)

12. Kumar V., Sharma T. P. Structural and optical properties of sintered $\mathrm{CdS}_{x} \mathrm{Se}_{1-x} \mathrm{~S}$ films. J. Phys. Chem.
Sol., 1998,v.59(8),p.1321.DOI:https://doi.org/10.1016/ S0022-3697(98)00035-3

13. Meteleva Ju. V., Novikov G. F. Fabrication and microwave photoconductivity of CdSe semiconductor films. Semiconductors, 2006, v. 40(10), pp. 1137-1144. DOI: https//doi.org/10.1134/S1063782606100034
Самофалова Татьяна Владимировна - к.х.н., доцент кафедры общей и неорганической химии, Воронежский государственный университет, Воронеж, Российская Федерация; e-mail: TSamofalova@bk.ru. ORCID iD: 000-0002-42774536.

Семенов Виктор Николаевич - д. х. н., профессор, заведующий кафедрой общей и неорганической химии, Воронежский государственный университет, Воронеж, Российская Федерация; e-mail: office@chem.vsu.ru. ORCID iD: 00000002-4247-5667.

Проскурина Елена Юрьевна - к. х. н., ассистент кафедры общей и неорганической химии, Воронежский государственный университет, Воронеж, Российская Федерация; e-mail: helko7@ yandex.ru. ORCID iD: 0000-0002-6149-1398.

Товарушкина Лидия Вадимовна - магистрант кафедры общей и неорганической химии, Воронежский государственный университет, Воронеж, Российская Федерация; e-mail: lidia.tovarushkina@yandex.ru. ORCID iD: 0000-0001-72912859.

Лукин Анатолий Николаевич - к. ф-м. н., доцент кафедры физики твердого тела и наноструктур, Воронежский государственный университет, Воронеж, Российская Федерация; еmail: alukin@chem.vsu.ru. ORCID iD: 0000-00016521-8009.

Никитин Леонид Николаевич - к. т. н., доцент кафедры конструирования и производства радиоаппаратуры, Воронежский государственный технический университет, Воронеж, Российская Федерация; e-mail:1.n.nikitin@mail. ru. ORCID ID: 0000-0002-0632-3041.
Tatyana V. Samofalova - Cand. Sci. (Chem.), Associate Professor of the Department of General and Inorganic Chemistry, Voronezh State University, Voronezh, Russian Federation; e-mail:TSamofalova@ bk.ru. ORCID iD: 000-0002-42774536.

Victor N. Semenov - Dr. Sci. (Chem.), Full Professor, Head of the Department of General and Inorganic Chemistry, Voronezh State University, Voronezh, Russian Federation; e-mail: semenov@ chem. vsu.ru. ORCID iD: 0000-0002-4247-5667.

Elena Yu. Proskurina - Cand. Sci. (Chem.), Assistant of the Department of General and Inorganic Chemistry, Voronezh State University, Voronezh, Russian Federation; e-mail: helko7@yandex. ru. ORCID iD: 0000-0002-6149-1398.

Lydia V. Tovarushkina - master's student of the Department of General and Inorganic Chemistry, Voronezh State University, Voronezh, Russian Federation; e-mail: lidia.tovarushkina@yandex.ru.ORCID iD: 0000-0001-7291-2859.

Anatoly N. Lukin - Cand. Sci. (Phys.-Math.), Associate Professor of the Department of Solid State Physic and Nanostructures, Voronezh State University, Voronezh, Russian Federation; e-mail: alukin@ chem.vsu.ru. ORCID iD: 0000-0001-6521-8009.

Leonid N. Nikitin - Cand. Sci. (Eng.), Associate Professor of the Department of Design and Production of Radio Equipment, Voronezh State Technical University, Voronezh, Russian Federation; email: l.n.nikitin@mail.ru. ORCID ID: 0000-00020632-3041. 